\title{
Torsion of Ovarian Tumor in the Elderly: About a Case
}

\author{
Amadou Bah1", Ibrahima Diakite1, Amadou Maiga1, Boubacar Yoro Sidibe1, Madiassa Konaté1, \\ Zakari Saye1, Boureima Kelly', Tany Koné1, Siaka Konate1, Arouna A. Doumbia1, Bathio Traore1, \\ Boubacar Karembe', Mohamed Lamine Diakite', Amadou A. Traoré1, Abdoulaye Diarra1, \\ Moustapha Issa Mangane², Abdoul Hamidou Almeimoune², Bakary T. Dembélé1, \\ Alhassane Traoré ${ }^{1}$, Lassana Kanté1, Adégné Pierre Togo ${ }^{1}$
}

${ }^{1}$ General Surgery Department, University Hospital of Gabriel Touré, Bamako, Mali

${ }^{2}$ Anesthesia and Reanimation Department, University Hospital of Gabriel Touré, Bamako, Mali

Email: *bah.amadouh@yahoo.fr

How to cite this paper: Bah, A., Diakite, I., Maiga, A., Sidibe, B.Y., Konaté, M., Saye, Z., Kelly, B., Koné, T., Konate, S., Doumbia, A.A., Traore, B., Karembe, B., Diakite, M.L., Traoré, A.A., Diarra, A., Mangane, M.I., Almeimoune, A.H., Dembélé, B.T., Traoré, A., Kanté, L. and Togo, A.P. (2020) Torsion of Ovarian Tumor in the Elderly: About a Case. Surgical Science, 11, 69-73.

https://doi.org/10.4236/ss.2020.114009

Received: February 17, 2020

Accepted: April 7, 2020

Published: April 10, 2020

Copyright $\odot 2020$ by author(s) and Scientific Research Publishing Inc. This work is licensed under the Creative Commons Attribution International License (CC BY 4.0).

http://creativecommons.org/licenses/by/4.0/

\begin{abstract}
We report a case of torsion of an ovarian tumor in a 68-year-old woman with no medical and surgical history. The diagnosis was made in front of an intermittently painful pelvic mass. The treatment consisted of a left annexectomy; the anatomopathological examination revealed a fibro-inflammatory and hemorrhagic cyst. Postoperative results were simple with a 12-month follow-up.
\end{abstract}

\section{Keywords}

Tumor, Ovary, Cyst, Surgery

\section{Introduction}

The ovarian tumor is an uncontrolled proliferation of cells at the expense of ovarian tissue. Adnexal Torsion is an uncommon pathology, but the gonadal risk is the same as for testicular torsion [1] [2]. It can be benign with a good prognosis or, on the contrary, malignant requiring adjuvant treatment to surgery. In all cases, it can be complicated by torsion, producing a surgical emergency scene, especially in elderly women exposed to defects. We report a case that we received in emergency for an acute surgical abdomen. The aim of our study was to display our management approach of ovarian tumor torsion in an elderly person.

\section{Observation}

It was a 68-year-old female patient with no known particular pathological history. She was urgently received for painful abdominal distension of sudden onset, 
evolving since 48 hours with a type of intense, fixed, permanent torsion accompanied by nausea, urinary type of pollakiuria. Moreover, she reported having similar states that quickly resolved. On physical examination, the abdomen was distended, asymmetrical by the presence of a median pelvic arching, regular, firm and heightened sensibility on mobilization. On pelvic contact, the uterus was atrophic, the pelvis was filled with a mass of fixed aspect and painful with non-lateralized mobilization. The lymph node areas were free and the rest of the examination was unremarkable. We thus put forward the diagnostic hypothesis of:

* Torsion of ovarian tumor

* Mesenteric tumor

The abdomino-pelvic ultrasound revealed a large tumor at the expense of the left ovary in the process of necrobiosis (Figure 1 and Figure 2).

The diagnosis of torsion of ovarian tumor was accepted.

Once the surgical indication was given, we performed a median laparotomy below the umbilical under general anesthesia. At the cœliotomy, the exploration permitted to reveal a voluminous left ovarian tumor having undergone a twist to 3 turns of the coil adhering to the sigmoid and to the uterine fundus measuring $15 \mathrm{~cm}$ in diameter (Figure 3 and Figure 4). The uterus was normal and so was the rest of the exam. We performed a left annexectomy with simple hemostatic control. The histology of the operating piece was in favor of an unilocular fibro-inflammatory and hemorrhagic cyst without vegetation referring to serous cystadenoma.

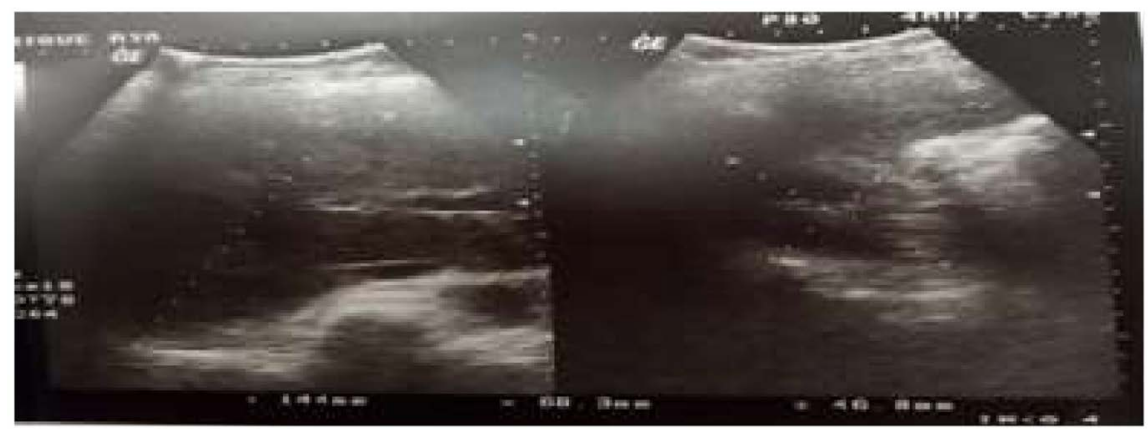

Figure 1. Ultrasonographic picture of left ovarian tumor torsion.

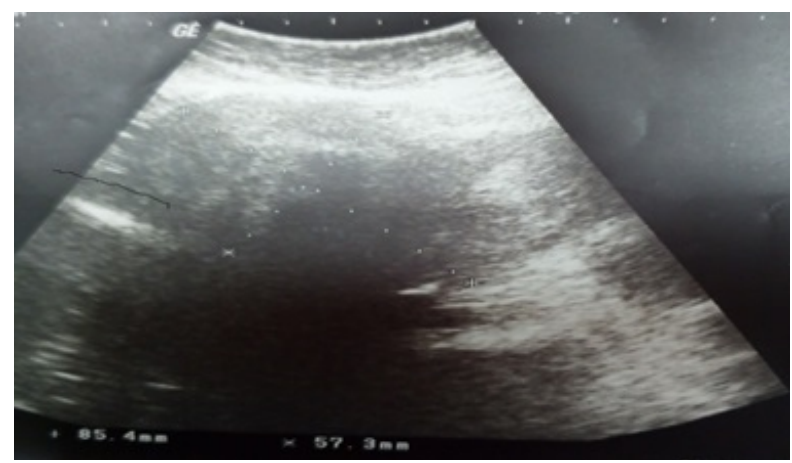

Figure 2. Ultrasonographic picture of left ovarian torsion tumor. 


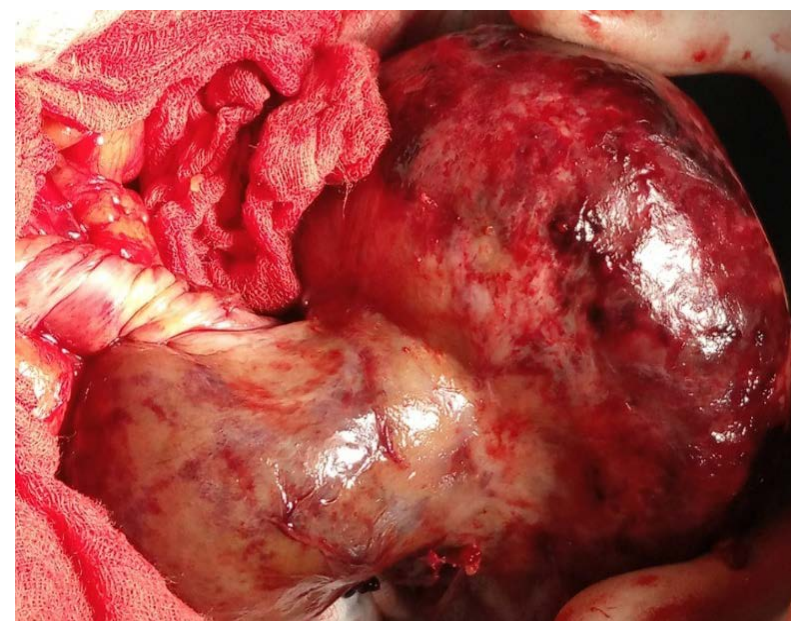

Figure 3. Preoperative of ovarian torsion tumor.

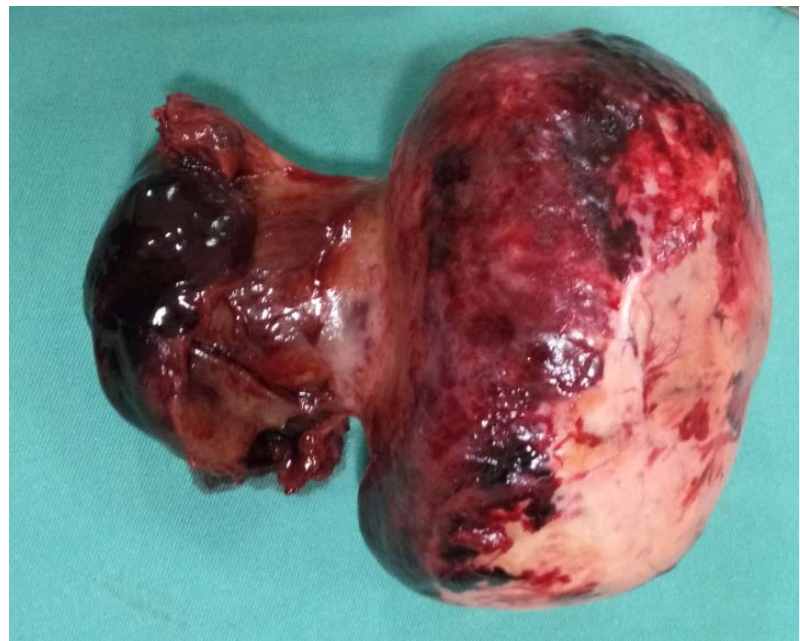

Figure 4. Postoperative specimen of ovarian torsion tumor.

The surgical outcome was simple, and patient discharging was approved at $3^{\text {rd }}$ post-operative day. At 24 months follow-up, any clinical and para-clinical complication wasn't recorded.

\section{Discussion}

The discovery of an adnexal mass in the post-menopausal period is a frequent situation and involves about $15 \%$ to $20 \%$ of this population, of which one-third constitutes malignant tumors [3]. In the literature, ovarian malignant tumor involves $36.8 \%$ of women after menopause [4]. Torsion is a common mechanical complication of the ovarian tumor. Compared to gonadal risk, all types of torsion don't involve the same gravity [5] [6]. The ovarian cyst is the prerogative of women of childbearing age. Any increase in the weight of the adnex can also cause the tender to twist. Thus, ovarian cysts, particularly dermoids, predispose to adnexal torsion and are the main etiology. The incidence of adnexal torsion in women with benign cystic teratomas is $3.5 \%$. Benign ovarian cysts are the most 
common cause of torsion than ovarian cancer; these latters have tendancy to invade adjoining tissues. Interviewing will endeavor to search for severe pain with abrupt onset. However, the abrupt onset mode is inconsistent and reportedly lacking in half of patients. The location of lumbar pain could be explained by sensory innervation of the ovary. This lumbar irradiation can however be a source of confusion with differential diagnoses of urological origin. In almost $70 \%$ of cases of tender torsion, there are signs associated with nausea and vomiting. They may be related to a vagal reflex secondary to the intensity of the pain or to peritoneal irritation. Diagnostic of adnexal torsion remains a challenge, due to poor specifity of its semiology [7]. The specificity of computer tomography (CT) and magnetic resonance imaging (MRI) is greater than 90\% [8]. CT and MRI are more characteristic. They reveal a large irregular tumor of mixed appearance, the solid part consisting of numerous calcifications with coarse contours and disseminated fatty tissue [9]. The preoperative diagnosis of adnexal torsion is difficult as the literature draws. Clinical examination using pelvic examinations reveals a lateral uterine mass in more than half of the cases [10]. The presence of a lateral uterine mass is noted in $41 \%$ to $70 \%$ of cases on clinical examination. The presence of peritoneal irritation is found when the adnexa becomes necrotic. In the various series studying the efficiency of the preoperative diagnosis, it is only accurate in $23 \%$ to $66 \%$ of cases, while the suspicion of an adnexal torsion requires emergency surgery [11]. In the event of suspicion of adnexal torsion, surgical laparoscopic exploration is recommended in emergency [7]. If diagnostic is confirmed, adnexectomy is recommended in menopause women. According to some series, the occurrence of adnexal torsion respectively involves $4.5 \%$ and $5.2 \%$ of patients; these patients clinically present acute surgical abdomen manifestation which is further confirmed by surgical exploration [12] [13].

This would be explained by a great disparity in the pattern of the disease behaviour. There is no correlation between hyperleukocytosis and tissue necrosis. The diagnosis of certainty of adnexal torsion can only be affirmed intraoperatively, whether by laparoscopy or laparotomy. In the absence of a contraindication, laparoscopy should be the preferred route, including in the event of pregnancy. Treatment must be quick and depends on the histological type [14] [15].

\section{Conclusion}

Torsion of the adnexa is a frequent complication of ovarian tumor; its diagnosis requires reliable knowledge of its semiology. In recent years, the contribution of new diagnostic methods is of benefit to medical professional for quick and accurate diagnosis. When diagnosing, adnexal torsion demands emergency care.

\section{Conflicts of Interest}

The authors declare no conflicts of interest regarding the publication of this paper. 


\section{References}

[1] Chang, H.C., Bhatt, S. and Dogra, V.S. (2008) Pearls and Pitfalls in Diagnosis of Ovarian Torsion. Radiographics, 28, 1355-1368. https://doi.org/10.1148/rg.285075130

[2] Growdon, W.B. and Laufer, M.R. (2013) Ovarian and Fallopian Tube Torsion. Uptodate, 4, 1-18.

[3] Dorum, A., Blom, G.P., Ekerhovd, E. and Grqnberg, S. (2005) Prevalence and Histologic Diagnosis of Adnexal Cyst in Post Menopausal Women: An Autopsy Study. American Journal of Obstetrics \& Gynecology, 192, 48-54. https://doi.org/10.1016/j.ajog.2004.07.038

[4] Goldstein, S.R. (1996) Postmenopausal Adnexal Cysts: How Clinical Management Has Evolved. American Journal of Obstetrics \& Gynecology, 175, 1498-1501. https://doi.org/10.1016/S0002-9378(96)70097-2

[5] Huchon, C. and Fauconnier, A. (2010) Adnexal Torsion: A Literature Review. Journal of Obstetrics \& Gynecology and Reproductive Biology, 150, 8-12. https://doi.org/10.1016/j.ejogrb.2010.02.006

[6] Charles, A., Dinarello, C.A. and Reuven, P. (2012) Fever and Hyperthermia. In: Longo, D.L., Fauci, A.S., Kasper, D.L., Hauser, S.L., Jameson, J.L. and Loscalzo, J., Eds., Harrison's Principles of Internal Medicine, McGraw-Hill, New York, 143-158.

[7] Deffieuxa, T., Thubert, C., Huchon, G., Demoulin, A., Rivain, L., Faivre, E. and Trichot, C. (2013) Complications des tumeurs ovariennes présumées bénignes. Journal de Gynécologie Obstétrique et Biologie de la Reproduction, 42, 816-832. https://doi.org/10.1016/j.jgyn.2013.09.036

[8] Fujii, S., Kaneda, S., Kakite, S., et al. (2011) Diffusion-Weighted Imaging Findings of Adnexal Torsion: Initial Results. Eur J Radiol, 77, 330-334.

https://doi.org/10.1016/j.ejrad.2009.07.040

[9] Nishida, M., Kowveno, Y., Yuga, A., Nasu, K., Matsumoto, H. and Narahara, H. (2014) Three Cases of Immature Teratoma Diagnosed after Laparoscopic Operation. Clinical Medicine Insights. Case Reports, 7, 91-95. https://doi.org/10.4137/CCRep.S17455

[10] Shukunami, K., Nishijima, K., Orisaka, M., Yoshida, Y. and Kotsuji, F. (2004) Acute Abdomen in a Jehovah's Witness with Chronic Anemia. The American Journal of Emergency Medicine, 22, 242-243. https://doi.org/10.1016/j.ajem.2004.02.026

[11] Steven, M. and John, I. (2012) Disorders of Granulocytes and Monocytes. In: Longo, D.L., Fauci, A.S., Kasper, D.L., Hauser, S.L., Jameson, J.L. and Loscalzo, J., Eds., Harrison's Principles of Internal Medicine, McGraw-Hill, New York, 472-482.

[12] Zilfi, W. (2012) Les tumeurs ovariennes: Aspects épidémiologiques, diagnostiques et thérapeutiques. Thèse de médecine, Université Cadi Ayyad, Marrakech, N71.

[13] Sando, Z., Mboudou, E., Fouogue, T.J., Nganwa, G., Tchuendem, J., Essame, J.L., et al. (2010) Profil clinique et anatomopathologique des cancers de l'ovaire à Yaounde, Cameroun. Clinics in Mother and Child Health, 7, 1183-1188.

[14] Le Goarant de Tromelin, J., Deruelle, P., Lucot, J.P. and Collinet, P. (2005) Évaluation de la prise en charge des tératomes immatures de l'ovaire. À propos de trois cas et revue de la littérature. Gynécologie Obstétrique \& Fertilité, 33, 594-599. https://doi.org/10.1016/j.gyobfe.2005.07.018

[15] Sait, K. and Simpson, C. (2004) Ovarian Teratoma Diagnosis and Management: Case Presentations. Journal of Obstetrics and Gynaecology Canada, 26, 137-142. https://doi.org/10.1016/S1701-2163(16)30489-3 